\title{
Conjugate reinforcement of operant responding in infants'
}

\author{
LEWIS P. LIPSITT, LINDA JOHNSON PEDERSON AND CLEMENT A. DELUCIA
}

BROWN UNIVERSITY

Two studies are reported in which visual conjugate reinforcement induced operant behavior in infants. Responses diminished and increased appropriately when reinforcement was withdrawn and reintroduced. Conjugate re inforcement, involving direct control of reward intensity by $S$ 's behavior rate, has promise in the study of infant learning processes.

In learning studies with infants, as with other organisms, various environmental events are sought which promote and sustain some measured behavior. Since extreme conditions of appetite or punishment are rarely used in human studies, such research often capitalizes on the effectiveness of sensory stimulation per se and of social reinforcers. The importance of such reinforcers for human functioning has been dealt with under headings such as "competency striving" (White, 1959), "curiosity motivation" (Butler, 1953), or "'manipulation drive" (Harlow, Harlow, \& Meyer, 1950), and Ss are said to have need for sensory input and opportunity to experience "recognitive familiarity" (Hunt, 1965). However, in studies involving sensory input as reinforcement rather than more vital consequences of response, reinforcers often lose their effectiveness, due to adaptation or boredom, before the associative process has been demonstrated or explored in depth (Lipsitt, 1963). Thus many infant operant studies are of short duration and few have been sustained for a sufficient period to enable extensive parametric investigations.

Recently, Lindsley and co-workers (Lindsley, Hobika, and Etsten, 1961; Lindsley, 1962, 1963) investigated a type of reinforcement that shows promise in infant conditioning work. Conjugate reinforcement involves the presentation of a continuously available event contingent upon response, such that the event's intensity varies directly and immediately with response rate. The prototype is the hand-generator flashlight in which illumination intensity is controlled directly by the response rate and pressure on a trigger or dynamometer handle. Relative to episodic schedules of reinforcement provided by delivery of pellets or candies, or of punitive circumstances with definitive onsets and offsets, the conjugate type of response-consequent permits (1) closer analysis of periodic changes in the value of reinforcing stimuli, and (2) maintenance of the $S$ in the situation for longer periods.

This report describes two studies involving a visual conjugate reinforcing device with year-old children. The rapidity with which some ss acquired operant behavior under the control of this reinforcer, and the readiness with which Ss extinguished when reinforcement was withdrawn, suggest that such procedures should be explored at earlier age levels and for longer periods than those in this preliminary work.

\section{Apparatus and Method}

In all, 44 Ss within one week of 12 months oid were introduced to the conjugate reinforcement situation, 22 under Procedure I and 22 under Procedure II. Of the first $22 \mathrm{Ss}, 10 \mathrm{Ss}$ met all criteria for retention and are here reported as a group. In Procedure II, 15 Ss completed the procedures.

The Ss were seated in an infant chair attached to the apparatus containing the operant manipulandum, a clear plastic panel measuring 8 by 9 in mounted on a box ( 18 by 18 by 12 in). Response to the manipulandum activated a special power supply, designed to vary the light intensity in the viewing box through changes in response rate, and consisting of a pulse-averaging circuit and a 110-V. phasecontrolled power unit. The response consequent was activation of a 120-watt light source, and $S$ could view whatever stimulus had been placed in the otherwise dark box. Reinforcement, or opportunity to see, was proportionate to the S's response rate, and transition from low to high brightness (and vice versa) occurred gradually rather than in step-wise fashion. No control was attempted over non-linearity between rate and brightness, but apparatus adjustments made possible the selection of the rate required to maintain full brightness. In the present study, when the reinforcer was connected (during conditioning), 2-3 responses per second produced and maintained full brightness. In the viewing box a colorful clown picture was mounted on a 4-in diameter disc, 2.5 in behind the manipulandum, rotating continuously at a rate of $30 \mathrm{rpm}$. The room was lighted by a shielded 25-watt lamp in front of the box, out of S's reach and direct view.

Cumulative response records were obtained by the reading of an electrical counter in an adjoining room every $15 \mathrm{sec}$. In Procedure I, a session consisted of a 15-sec. Baseline period, followed by $5 \mathrm{~min}$. Conditioning (conjugate reinforcer operative), a $1 \mathrm{~min}$. Extinction (reinforcer inoperative), then $2 \mathrm{~min}$. Reconditioning, and $1 \mathrm{~min}$. Re-extinction periods. In Procedure II, Baseline was variable in duration but constant in number of responses required, lasting as long as necessary to obtain five responses, with Ss being dropped from study if five were not obtained within $3 \mathrm{~min}$. In Procedure II, Baseline was followed by $5 \mathrm{~min}$. of Conditioning, two of Extinction, two of Reconditioning, and one of Re-extinction.

The mother put the $S$ in the chair and sat in a chair on S's right. She was asked not to speak unless $S$ cried, in which case she could comfort him in any way she wished. The $\mathrm{E}$ entered the adjoining recording room behind a one-way mirror.

Results

Figure 1 shows the average cumulative responses for $10 \mathrm{Ss}$ finishing Procedure I. Five of the initial $22 \mathrm{Ss}$ were eliminated because of crying, three because of interference by mother, one because of procedural error, and three for failing to make any panel responses in the first $3 \mathrm{~min}$. of Conditioning.

To test the effects of reinforcement and its withdrawal, related t-tests compared rate measures in different experimental periods. The difference between Baseline rate and the rate reached in the 5 th min. of Conditioning was reliable $(t=8.00, d f=9, p<.001)$. The rate for every $\mathrm{S}$ increased from Baseline to this period. A comparable 


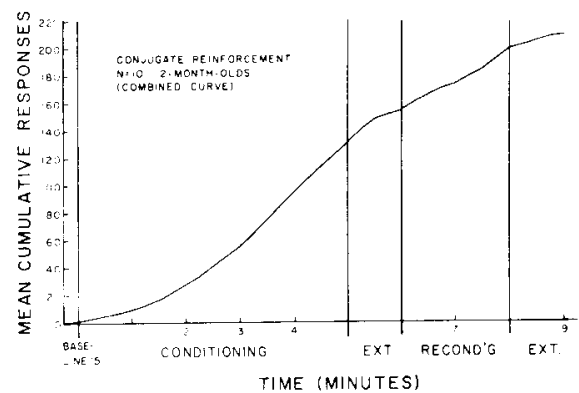

Fig. 1. Combined cumulative record for $\mathbf{N}-10$ under Procedure $I$.

test was run between the 1 st-min. and 5 th-min. rates; this difference was reliable $(t=2.70, d f=9, p<.05)$, with 9 of 10 Ss showing a rate increase from the 1st to 5 th min. Reduction in response rate from the 5 th $\mathrm{min}$. of Conditioning to the 1st Extinction min. was not reliable $(t=1.32, \mathrm{df}=9)$ although 6 out of $10 \mathrm{Ss}$ did show a rate decline. Although a group increase in responding occurred between the first Extinction period and Reconditioning, this effect was not reliable. However, following Reconditioning, Re-extinction produced another drop in responding $(t=3.99, p<.001)$ with no Ss showing an increase in responding.

In succeeding work, it was decided to extend Extinction from 1 to 2 min., and change Baseline from a constant $15 \mathrm{sec}$. to a variable period, the time required for five responses. Thus, each $\mathrm{S}$ began the 1 st min. of Conditioning as soon as five non-reinforced responses to the punel occurred. No Ss were retained who failed to emit five responses in $3 \mathrm{~min}$. or who cried prior to making these responses. Of 22 remaining Ss, 15 constitute the Procedure II group, one being eliminated because of mother interference ${ }_{8}$ one because of procedural error, and five because of crying during Conditioning.

Baseline performance was converted to a rate measure: If $\mathrm{Ss}$ took $12 \mathrm{sec}$, in which to make 5 responses, the rate was $25 / \mathrm{min}$. Figure 2 shows the group performance. Raite increased from early Conditioning to late,

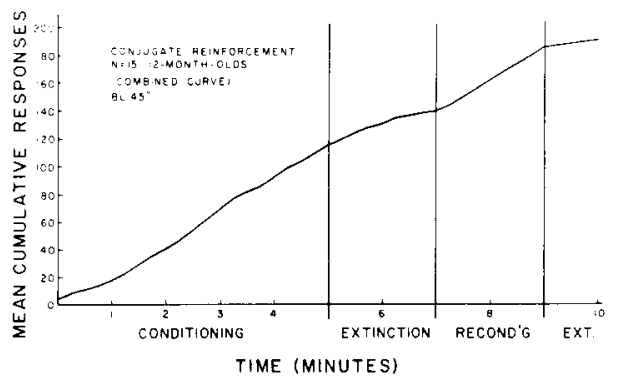

Fig. 2. Combined cumulative record for $\mathrm{N}-15$ under Procedure II. decreased when reinforcement was withdrawn, increased when reinforcement was reinstated, and decreased again under the second Extinction condition. These propositions were tested with t-tests. From Baseline to the 5 th $\mathrm{min}$. of Conditioning, response rate increased significantly $(t=2.22, d f=14, p<.05)$. The difference between Baseline and the full 1st-min. Conditioning rate was reliable $(t=5.15, d f=14, p<.01)$. Although the rate difference between the 1st and 5 th min. of Conditioning missed significance $(t=1.45$, $\mathrm{df}=14$ ), that between the 1 st and 4 th $\min$. was reliable $(t=3.00, d f=14, p<.01)$.

Rate declined from the 5th Conditioning min. to the 2nd Extinction $\min$. $(t=2.32, d f=14, p<.05)$. Similarly the rise in rate in reverting to reinforcement was reliable at the .05 level $(t=2.47, \mathrm{df}=14)$. Again, when Extinction was reinstituted, behavior rate dropped significantly (2nd Reconditioning min.vs. Re-extinction, $\mathrm{t}=3.32, \mathrm{p}<.01$ ).

The setting in which the present data were collected made $S$ available for only about $15 \mathrm{~min}$. each, and there was little or no time for the usual shaping-up process that is brought to bear on a recalcitrant experimental subject. Consequently, the number of drop-outs was rather large. For those Ss remaining through the entire procedure, however, it is noteworthy how effective the conjugate reinforcement seems to be. Ss who fail to meet one or the other criterion for retention may reflect true individual differences, themselves of predictive significance. Further studies should explore variations of the present preliminary techniques, using other visual reinforcers in motion and experimental periods of greater duration.

\section{References}

Butler, R. A. Discrimination learning by rhesus monkeys to visual exploration motivation. J. comp. physiol. Psychol., 1953, 46, 95-98.

Harlow, H. F., Harlow, M. K., \& Meyer, D. R. Learning motivated by a manipulation drive. J. exp. Psychol., 1950, 40, 228-234.

Hunt, J. McV. Traditional personality theory in the light of recent evidence. Amer. Scient., 1965, 53, 80-96.

Lindsley, O. R. A behavioral measure of television viewing. $J$. advert. Res., 1962, 2, 2-12.

Lindsley, o, R. Experimental analysis of social reinforcement: terms and methnds. Amer. J. Orthopsychiat., 1963, 33, 624-633.

Lindsley, O. R., Hobika, J.H., \& Etsten, B. E. Operant behavior during anesthesia recovery: a continuous and objective method. Anesthesiology, 1961, 22, 937-946.

Lipsitt, L. P. Learning in the first year of life. In L. P. Lipsitt \& C. C. Spiker, (Eds.), Advances in child development and behavior, 1963, 1, 147-195.

White, R. W. Motivation reconsidered: the concept of competence. Psychol. Rev., 1959, 66, 297-333.

\section{Note}

1. These studies were supported in part by USPHS grant NB 04268. The writers wish to thank Sally Ann Serunian for her aid in data collection. 